\title{
Teachers' embodied presence in online teaching practices
}

\author{
Karin Bolldén
}

\section{Linköping University Post Print}

N.B.: When citing this work, cite the original article.

This is an electronic version of an article published in:

Karin Bolldén, Teachers' embodied presence in online teaching practices, Studies in Continuing Education.

Studies in Continuing Education is available online at informaworld ${ }^{\mathrm{TM}}$ :

http://dx.doi.org/10.1080/0158037X.2014.988701

Copyright: Taylor \& Francis (Routledge): SSH Titles

http://www.routledge.com/

Postprint available at: Linköping University Electronic Press

http://urn.kb.se/resolve?urn=urn:nbn:se:liu:diva-112886 


\title{
Teachers' embodied presence in online teaching practices
}

\author{
Karin Bolldén \\ Department of Behavioural Sciences and Learning, Education and Adult Learning, Linköping \\ University, Sweden
}

\begin{abstract}
This study aims to examine teachers' embodiments online. The analysis is based on online ethnographic data from two online courses in higher education settings using different ICTs. The perspective of practice theory and the concepts of being a body, having a body and instrumental body (Schatzki 1996) were used to analyse how teachers step into embodied presence. The embodied presence depends on both teacher judgements and what the technology offers. The finding adds to the understanding of the concept of teacher presence online, in showing that teacher embodiment occurs online and furthermore that the body could be understood as multiple. The result also shows how online and offline bodies hang together, actualising the offline body in the online setting, which in turn raises questions on the dualism of online and offline. Teachers also deliberately used their embodiments and bodily traces online in order to sustain presence and to bring about certain teaching practices. Their bodily positioning signalled what kind of teaching that would take place. A deliberate positioning of the online body in a virtual world also helped to reduce the complexity of the arrangements for the students.
\end{abstract}

Keywords: teacher embodiment; teaching practices; sociomaterial; online ethnography; higher education

\section{Introduction}

Currently, teaching and learning online is a common phenomenon within higher education. When teaching online, a new and different environment relative to offline settings is created. The presence of other students and the teacher is considered essential to avoid feelings of isolation and to create a fruitful online learning environment (Lehman and Conceição 2010; Hrastinski 2009). Teaching presence is often discussed in previous literature with the concepts of social presence and cognitive presence (Garrison, Anderson, and Archer 2000). Teaching presence focuses on teachers' planning, structuring and conducting of teaching and interventions in online environments. Social presence concerns social and emotional aspects, whereas cognitive presence concerns students' ability to create meaning through communication in an educational setting. Lehman and Conceição emphasise that presence is important in online settings but that it is not automatically created, given that 'in the virtual 
space, presence needs to be intentionally created' $(2010,11)$. In sum, online presence is important for students, and there is a specific focus on social, emotional and cognitive presences, as well as on teachers' planning and intervention. A less discussed aspect of presence in relation to teaching is that of embodiment in online environments.

Over the last few decades, there has been an on-going debate concerning whether online environments are disembodied and whether people leave their bodies behind when going online (Sundén 2002). There is now a growing body of literature claiming that online environments are embodied environments, even when these environments are only textbased. Sundén examined a text-based online environment and concluded that the online body could be understood to have a textual dimension. She claims that one has to 'type oneself into being' $(2002,13)$ in this type of environment and that 'texts in a sense become bodies' $(2002$, 29). Other researchers have also highlighted how text becomes bodies, for example, Boellstorff (2008) termed this as textual embodiment. Boyd (2008) used the concept of profile body to describe bodies that consist of both text and photographs.

Taylor's perspective when discussing embodiment in the virtual world is that presence is grounded in the avatars, which 'prove to be the material out of which relationships and interactions are embodied' (2002, 41, italics in original). The user participates online in the shape of an avatar that is a text, icon, image or a three dimensional shape. Consistent with this line of reasoning, it could be that a teacher's digital body is a way of teaching and showing presence in an online setting. Thus, Taylor (2002) and Sundén (2002) reason that online environments are spaces where embodiment occurs. Embodiment is also perceived as a way to create presence, or Taylor states: 'the body through which presence is being constructed is not simply the corporeal [offline] one, but the digital [online one] as well' $(2002,42)$.

The research examining how teachers embody their presence online and how this relates to their teaching is still scarce. Steils highlighted that research examining online embodiment in educational settings is needed when stating the following: 'it thus remains unknown how conventions of real-world education, combined with learner and tutor perspectives, impact upon virtual world representations' $(2011,28)$. Landri (2012) has also highlighted that the body is in the background in the educational field, but that practice theories can place it in the foreground. Mol has used a practice theoretical approach in order to study how the disease of atherosclerosis was enacted in Dutch hospitals. Mol's main conclusion was that the body is more than one; it is manifold, however not fragmented. She contended that since the body is multiple it 'begs the question of how they are related' $(2002,5)$.

A related area to presence and embodiment is identity. Bayne (2005) studied teachers' identity construction in virtual learning environments and found that they constructed themselves as teachers being in control and being authority figures. Bayne suggested that these constructions could be an answer to that the technology creates a symmetrical relation between the people involved. The present paper, however, does not focus on teachers' identity, but instead on their presence online in terms of embodiment. Furthermore, the analytical interest lies in analysing what the body looks like and how it is handled in the 
actual teaching situation. Thus, this paper concerns the professional capability in handling embodiment online. The research question examined is how teachers' embodiment in an online teaching setting can be described and analysed.

\section{Theoretical lens}

From a theoretical perspective, online teaching can be conceived in terms of sites that combine social practices and material arrangements which co-constitute each other. This perspective is helpful when analysing teaching in new material and social settings, such as different online environments. Sociomaterial approaches have gained increasing momentum in educational research (Fenwick, Edwards, and Sawchuk 2011). Theodore Schatzki's 'practice theory' is part of this turn to sociomaterial practice (Schatzki 2001) and has been used as a theoretical lens in this article. To start, a social practice is a set of organised actions conducted by humans. Schatzki (2002) terms these actions as bodily doings and sayings. In teaching, organised actions can concern what contents to choose and which teaching method to choose. Material arrangements are entities of different types, such as humans and artefacts. Moreover, there are a number of social relations among organised practices and arrangements, two of which are intentionality and prefiguration. Intentionality is when a human entity exhibits thoughts, actions, feelings or understandings towards another entity of any kind. Prefiguration is when a practice with its arrangement is making activities more or less possible to happen. The body and embodiment become central when using practice theory as a theoretical lens (Schatzki 2001; Reckwitz 2002). It is the human body that conducts certain doings and sayings that constitute the activities in a practice. Further, the human entity is also perceived as part of the material arrangement and material entities include bodies (Schatzki 2012). Schatzki writes about three dimensions or components of embodiment that describe what embodiment might refer to, namely to be a body, to have a body and the instrumental body. According to Schatzki being a body:

is to be able both to perform bodily doings and sayings and to experience bodily sensations and feelings.

Of note is that being a body is but one component of embodiment, one that emphasizes the lack of experiential and conceptual disunity a person has with her body in normal circumstances of acting and experiencing. $(1996,43)$

Schatzki's concept of being a body could be understood as a normal mode or state that involves not having to think about the body when doing, saying, feeling, or experiencing something. The body is mentally in the background when something is carried out. To have a body:

is made evident in situations of breakdown, malfunction, discomfort, and incompetence, where the fact that one is a body manifests itself explicitly. In cases of (...) failure to achieve goals through physical effort (...) a person is forced to confront and deal with her body. Such experiences may also underlie her recognition of a distinction between herself and her body. Although this body is hers, she is not identical with it. Rather she has it. $(1996,43)$

My interpretation of the concept of having a body is not that it is a division of body and soul (or action and mind), but rather as a disruption between the human entity and the surrounding 
arrangement. Expressed differently, having a body comes to mind when there is a discrepancy between human intentionality and bodily performance in the material arrangement. Moreover, according to Schatzki the body is:

an instrumental body. It is through the performance of bodily actions that the performance of other actions is constituted or effected (....) Bodily performance is unceasingly instrumental in the achievement of a person's ends $(\ldots$.

There is no need for him to seize, occupy, or activate his body in order for bodily activity to occur. $(1996,44-45)$

Thus, by performing specific doings in certain situations, a person's body becomes a tool to accomplish something more. I interpret Schatzki's (1996) notion about the instrumental body as the body's performances accomplish intentional ends. One example is pressing keys on a keyboard to post a message in a course folder, which is done to accomplish the ends of teaching. Schatzki (2002) mentions the close relation between the human body and artefacts, stating that actions conducted by the human body can be accompanied by different forms of extensions or prostheses. This is consistent with but not in direct correspondence to Haraway (1991), who uses cyborg as a concept for dissolving the division of human and machine. Schatzki (2002) also mentions the concept of cyborg when discussing mongrels as a type of artefact that would not exist without human activity. However, he does not discuss cyborgs in further detail. The body in online environments could be understood as a cyborg; pixels on a screen and in some cases accompanied by voice relayed through a headset. This online body can nevertheless be seen as a material entity, since virtual objects are just as material as physical objects (Jacobsson as quoted in Taylor 2002; Landri 2009; Orlikowski 2007). In this paper, I will focus specifically on the concepts of being a body, having a body, and the instrumental body to analyse how embodiment can be understood in the online teaching practice.

\section{Method}

This study has an online ethnographic approach, inspired mostly by Hine (2008) and Williams (2007). The paper is based on an analysis of two different university courses entirely carried out online, offered at different universities in Sweden. Settings that are very different in character have been chosen to provide variations in the realisation of online teaching practices regardless of their subject matter. Both courses were followed from their beginning to their conclusion via observation. Prior to observation, interviews with the teachers of the courses were conducted. Documents related to the courses were included as part of the empirical data.

The first setting is a course in a master's programme in education where the learning management system (LMS) (Piccoli, Ahmad, and Ives 2001) itslearning ${ }^{\odot}$ (IL) is used. IL is primarily based on asynchronous (i.e. non simultaneous) and text-based communication, in which discussion forums are a basic organisational form. The second setting is a singlesubject course in language using Second Life ${ }^{\circledR}$ (SL) as a platform. SL is a virtual world (Mawer 2011; Peachey et al. 2010), which means a platform built as a three-dimensional 
space in which the user participates as an avatar that can move and interact with other avatars. Communication is primarily synchronous (i.e. simultaneous), based on both audio and text, and involves public and private conversations.

The empirical data are built up from several sources. In-depth interviews were conducted with the teachers for both courses. The interviews had a semi-structured format and lasted between one and a half to two hours. These interviews were conducted prior to the observations and focused on attaining an overall understanding of the course and the teachers' intentions concerning choices of content and working forms. The interviews were transcribed verbatim and encompassed 47 pages. Excerpts from the interviews were translated into English. Document analyses have been conducted, as the empirical data included documents related to the courses, such as course syllabi and course web pages. Observation was conducted during the entirety of each course, focusing upon teachers' doings and sayings. Synchronous observations and recordings thereof have been done in the SL setting, meaning that observation has been done in real-time. The recordings amount to 20 hours. Field notes were also taken, comprising 211 pages. Asynchronous observations have been done in the IL setting, which means that observations have been done in retrospect, reading all the messages and documents posted on the platform, which amounts to 18 discussion forums, 508 threads, 2937 posts and approximately 20 documents. In conjunction with observations, informal conversations with the teachers were conducted.

The empirical data were imported to NVivo, where thematic analysis grounded in the empirical data has been made, where meaning units were interpreted and named. A second round of analysis was then conducted based on the previous analysis and through the lens of practice theory, generating theoretically grounded broader categories and themes (an illustrative example is provided in Table 1). The analysis has been characterised by a movement between the different sets of data, comparing and contrasting empirical data within the same type of data e.g. field notes, but also comparing and contrasting among different types of data, e.g. recordings and interviews. Both settings studied (i.e. the IL and SL settings) have also been analysed each one individually and together. Thus, the analysis was iterative and reflexive (Srivastava and Hopwood 2009).

Table 1. Illustrative example of the thematic analysis undertaken.

\begin{tabular}{|l|l|l|l|}
\hline Meaning unit & Code & Category & Theme \\
\hline $\begin{array}{l}\text { /..The teacher is } \\
\text { invisible... if there's } \\
\text { no text... so the } \\
\text { teacher has to be... it } \\
\text { requires a lot... } \\
\text { reading all those } \\
\text { messages and taking } \\
\text { care of (the students), } \\
\text { tracking all that are } \\
\text { not visible there, } \\
\text { encouraging them../ }\end{array}$ & & instrumental body & embodiment \\
\hline $\begin{array}{l}\text { /..I use podcasts... the } \\
\text { real function... is to }\end{array}$ & invisible and visible & instrumental body & \\
\hline
\end{tabular}


make sure to regard

those students who

could be anywhere...

It's okay... you are

still with us../

In the education course, two teachers participated in this study, and will be referred to as Teacher 1 and Teacher 2. There was one teacher for the language course, who will be referred to as Teacher 3. The teachers in both settings have freely chosen to participate in this study. Informed consent has been obtained in written form. Given ethical considerations, information that could reveal the identity of informants has been omitted. Each subsection for the results starts with a descriptive presentation and is followed by an analytical account.

\section{Results}

\section{Teachers stepping in - Being a body online}

In IL, the user is presented by name and has the option of adding several types of contact information, such as an email address and phone number. All participants have the option of presenting themselves by uploading a photo. The photos will be presented with the participants' names and their posts on the platform. Photos will also be shown on the personal information page that every participant has. On this page, there is a link to an ePortfolio where the participants can add content. In addition to these ways of presenting the users, it is also possible to write messages and provide others with more personal details.

Teacher 1 is embodied by an uploaded photo, which is a half-length portrait showing the teacher leaning his/her head against a child who is sitting in the teacher's lap. Part of the child's head and a bit of one of the eyes is visible, but the image appears to be cropped to focus on the teacher. Teacher 1 has included a message in the first discussion forum in the working group that Teacher 1 is responsible for, which provides some personal information e.g. birthplace and when moving to the current city of residence. Teacher 1 writes in a personal style, talking about preferred parts of Sweden, leisure activities and family. Thus, the text and photography complement each other, showing in two different ways the region in the world that Teacher 1 is from and that Teacher 1 is a parent.

Teacher 2 has not uploaded a photo; therefore, the image of a dummy, which is a grey silhouette of a body on a white background, appears when other participants look at the personal information page or read Teacher 2's posts on the discussion boards. The dummy can be perceived as a placeholder for a customised body and may be used as a default embodiment. In this sense, the system is assigning every user a default body, which the user can choose to customise. As this study show, this happens, but not always. The automatically generated ePortfolio lacks information and, therefore, appears to never have been used. So what is available is presentation through text only. Teacher 1 has written the first message for the course, which is a welcome message with information about the course. Teacher 1 also 
presents the teachers in the course by first and last name. Four days into the course, Teacher 2 contributes the first post in one of the discussion forums:

Hello everyone. After a couple of days of travelling with poor internet facilities, I am back and look forward to working with you all. I will follow your discussions regularly and contribute when I - or you, of course, - feel the need.

All the best,

Teacher 2's first name

Teacher 2's message is only available in the designated space for the working group that Teacher 2 is responsible for. The LMS in use makes available certain ways of presenting oneself, which are by name, photo and text. Yet, this does not mean that everyone does so or that everyone does it using all of the possible ways to present oneself.

In SL, there are two primary courses of action for embodiment. First, when creating an account, every user needs to choose an avatar, which is an online body, from a set of predefined ones. It is possible to choose the avatar's species from options, such as a human, vampire, robot or vehicle. When logging in, it is possible to alter the avatar completely or to adjust e.g. gender, age, height, eye colour, hairstyle and clothes. Second, every user has a profile where it is possible to write about oneself and one's interests and to upload pictures for both the avatar and an offline appearance. In addition to these two ways, the user also has a SL name, which is by default displayed above the avatar. When logged in, users can use both audio and text to communicate with others, thereby presenting themselves further.

Teacher 3 has chosen a human avatar that is casually dressed and fairly average in age. The avatar can be characterised as having a rather mundane embodiment. Sundén (2002) argues that even an average look involves choices, regardless of whether they are conscious. Some of the bodily characteristics overlap with Teacher 3's offline body, such as gender and clothing style. The profile is nearly empty, as only automatically registered information is evident, including SL birthday and groups that Teacher 3 belongs to in SL. Furthermore, a dummy in the form of a white silhouette on a grey background was shown in the profile since Teacher 3 had not uploaded an image. The teacher has chosen a first name that is similar but not in direct correspondence to the teacher's first name offline.

SL is the main technology used in Teacher 3's course, yet there is also a course homepage and a Facebook group that serve as supportive ICTs for the course. On the course homepage, the teacher provides guidance regarding how to use SL. This is done by a couple of videos in which Teacher 3, through the avatar shows viewers how to do things in SL. Teacher 3's offline embodiment is shown via an inset, most likely at the desk at the office. In this image, Teacher 3 is dressed slightly more formally. When inworld (i.e. when logged in to SL) Teacher 3 uses the offline name yet the avatar name can also be seen in the recording. Therefore, viewers can see both the avatar and the video image and hear the voice of the teacher synchronously. In some situations, Teacher 3 uses the avatar name during class, yet, most of the time, uses the offline name. In the Facebook group, the teacher has chosen a presentation with the offline name and a photograph in which the teacher is dressed in a similar way as in the videos on the course homepage. 
Thus, being a body online implies various degrees of embodiment. Both SL and IL are built in a way that makes embodiment mandatory to a certain degree. Teachers are offered various ways to become a body online in each respective system in addition to the mandatory options. Yet, the teachers do not use all of the ways to embody themselves. For these teachers, the online situation differs from the offline teaching situation, in which their bodily presence is an integrated part of their appearance. In the online settings, there is the option to leave the (offline) body and other characteristics behind to a more or lesser degree. Users who have the same appearance on- and offline are described as realistic users (Neustaedter and Fedorovskaya 2009 as quoted in Steils 2011), which is the case for at least Teacher 1 and Teacher 3 in this study. However, this does not mean that all of the characteristics offline are brought to the online setting but the online embodiment is to a greater or lesser degree linked to the offline body.

As is evident in the two settings, stepping into embodied presence online does not come by itself. In the SL setting, Teacher 3's response regarding the big challenges encountered when teaching online, part of the answer was the following: 'You have to find... okay... spontaneously, I would say that you need to find a way to be yourself...' (interview-03). Thus, to enter the online setting, teachers need to find a way to be themselves online. This means that something has to be done in order to be.

\section{I and it - Being and having a body online}

When teaching, thoughts of the body are seldom in the foreground. Perhaps, when failing to pull down a projector screen, awareness of having a short body length is realised. When analysing the data with regard to the concept of having a body, movements and awareness of the body are salient in the SL setting but not in the IL setting. Therefore, the analysis in this subsection will only focus on the SL setting.

From a practice theoretical lens, the body is part of the teaching practice and may be more prominent in the online than the offline setting. Being embodied as an avatar could be understood as a continuous movement between the dimensions of being and having a body. When applying these concepts to embodiment in the shape of an avatar, having a body is characterised as a state in which malfunctions or breakdowns occur between the online body and offline body, which controls the online embodiment. When no malfunction occurs but there is a greater degree of overlap between the online and offline body, this can be understood as being the online body. There are many examples in the SL setting when this movement occurs. The following excerpts exemplify these dimensions:

Excerpt 1

((Teacher 3 is trying to turn around so that $\mathrm{s} / \mathrm{he}$ sees what is going on behind him/her, namely, the slides that Teacher 3 is putting up on the screen.)) Teacher 3: Now then guys... Let me... Sorry, hold on a minute ((clears throat)) ((silence)). I'm just pressing the wrong buttons. That's better... ((sighs)) ((silence)) There we go, cause I'm trying to turn my, turn to look at my avatar... so I can see what's going on behind me... Em... ((clears throat)), now then... Let me start off by showing you roughly what's going on today (Field notes Setting 2 F_D2_SL_2012-02-29). 
Excerpt 2

((Teacher 3's avatar begins to spin)) Teacher 3: Hold on a minute, sorry about this, is my, my computer is being incredibly quick at the moment. It means that my avatar, if I'm not very careful, hold on a minute, it's doing something funny, my avatar, at the moment. My avatar, sort of like, spins around... There we go, stop doing that avatar, thank you. Hold on a minute, I'm gonna have to just walk forward a bit or do something, ((Teacher 3 walks into the wall and then into the screen)) to see if I can stop my avatar from... that's it avatar, stand still, there you go. Nice little avatar, do what you're supposed to do, right, yeah sorry about that (Field notes Setting 2 F_D2_SL_2012-03-14).

\section{Excerpt 3 \\ ((Teacher 3's avatar starts to turn from one side to the other)) Whoops, I'm sorry about that, my, I'm just trying to get my... avatar to behave itself again, em... (Field notes Setting 2 F_D2_SL_2012-03-28). \\ Excerpt 4 \\ Teacher 3: So, I shall sit me and myself down ((Teacher 3 sits down in the first row on the right-hand side of the aisle)) (Field notes Setting 2 F_D2_SL_2012-04-11). \\ Excerpt 5 \\ Teacher 3: I think, hold on a minute, sorry, sorry about that, my avatar went for a walk, here we go, here we go (Recording 20120209E at 23:55).}

The manner of naming oneself indicates whether there is a breakdown occurring. In the excerpts, Teacher 3 uses a range of personal pronouns. These denominations signal the dimensions of being and having a body. When being a body, pronouns like I and me (first person singular) are used, and when having a body, pronouns like it (third person singular) and my (possessive pronouns) are used. Expressing that the avatar does not behave, as in the third excerpt, clearly indicates that a breakdown is occurring. It appears that disruptions are made clear or explicit in the sayings.

The movement in the dimensions of being and having a body can be characterised as stepping in and out of the online embodiment. When being the online body, the teacher is immersed in the online setting. The concept of immersion is used to describe the feeling of being there in the online world (see, e.g. Castronova 2005). Teacher 3 is moving between these dimensions or possibly being in both dimensions simultaneously in the very same situation. Schatzki (1996) writes that being and having a body are closely intertwined as dimensions. This interweaving is salient in the previous excerpts, which show that the dimensions of being and having a body are present in the same sentence.

A common feature in all of the excerpts is that Teacher 3 comments upon the doings. Most of the breakdowns occur when Teacher 3 is moving around in the online setting. When the teacher is speaking with no bodily movement, breakdowns do not occur. Therefore, it is likely that having a body occurs when movement is involved. However, it is important to note that breakdowns do not occur every time movement happens. When Teacher 3 sits down on a chair, s/he could do it sometimes without mentioning it and this works fine. Yet, it still appears that having a body is connected to movement. This may be associated with managing the online embodiment, which is accomplished by pushing appropriate buttons and moving a mouse in synchrony with the on-going activities. The SL client (i.e. a program on a user's computer) changes over time via updates that are released on a regular basis. These updates 
typically result in new or adjusted ways of navigating inworld. Therefore, manoeuvring the online body is something that the teacher never really gets finished with. It is something that has to be learned repeatedly with the changes resulting from updates of the software. This is evident in the fifth excerpt, when Teacher 3 accidentally presses a button that causes the avatar to walk away, which was a new feature in the client programme when the observations was conducted for this study. Teaching in this type of environment requires knowledge and skills regarding how to manage a situation characterised by teaching subject matter and manoeuvring the body while having both in the foreground from time to time.

When analysing the data with regard to the concepts of being and having a body, it becomes clear that there is not one body in play during these situations. Rather, there are multiple bodies in play, including online and offline bodies, which overlap in certain degrees. Taylor describes a less overlap as being pulled back from the online setting: 'This feeling of being suddenly pulled back out of the virtual world highlights the fragility of multiple forms of embodiment, especially in relation to the digital' $(2002,44)$. This description is consistent with the perception of the dimension of having a body online. The following excerpts exemplify the view that being a body refers to both the on- and offline embodiments:

Teacher 3: I will just go and get my papers, and then I will be ready for you in just a moment (Recording 20120411A).

Here, Teacher 3 refers to the offline body, which is going to get some papers. In the following excerpt, Teacher 3 refers to the online body (or perhaps to the offline as well):

Teacher 3: I'm just gonna post a web address for you there ((writing in text chat: http://www.link.com)) (Recording 20120411A).

In the next excerpt, Teacher 3 refers to a paper, which is in front of the offline body, and to a picture, which is uploaded on the screen (located behind Teacher 3), in the online setting. Both the paper and picture are showing the same sheet:

Teacher 3: What I have in front of me is this mark sheet (Recording 20120411A).

Clearly, this may be a situation that has more than one body in play. The first excerpt shows that the offline body is invoked in the online setting. It also expresses a situation in which Teacher 3 is being a body. The second excerpt also expresses a situation in which Teacher 3 is being a body, yet there is a question regarding which one. It could be the offline body that is typing on the keyboard, yet the avatar also types in the air. Additionally, the link is posted in the open chat in the online environment. This could be understood as a situation of Schatzki's (1996) dimension of being a body, but where the dimension of being a body concern being several bodies at the same time. Excerpt three also refers to the offline body, which exemplifies the issue of several bodies. Both the online and offline bodies are denoted in the online setting. This indicates that it is needed to step away from the notion of being just one body and start thinking about being a body multiple (Mol 2002). This relates to the discussion of linkages between the online and offline environments. The online practice is not disassociated from the offline setting and body where the teacher dwells. Teaching online in these types of settings involves managing several bodies. 


\section{Prefiguring teaching practice - The instrumental body online}

When analysing the teachers' sayings and doings, their strategies for keeping themselves present during the course emerge, as shown in the following excerpt from the IL setting:

KB: $\quad$ I am wondering how you think it is, in general, to teach online...

Teacher 1: It is much more work than you think it would be... You really should give the teacher more time... The teacher is invisible... if there's no text... so the teacher has to be... it requires a lot... reading all those messages and taking care of (the students), tracking all that are not visible there, encouraging them, writing an, maybe perhaps quite meaningless such messages, hi I'm here, I'm reading... and such... (interview-01)

What this teacher expresses as meaningless messages could be understood as meaningless in terms of subject matter, but not when concerning online presence. By writing those messages, the teacher is signalling that $\mathrm{s} / \mathrm{he}$ is there and also expressing the invisible doings; that $\mathrm{s} / \mathrm{he}$ is reading the messages. Why the teacher is doing like this could be understood when looking at the properties of the technology used in the course. The LMS that was used allows teachers to track some of the students' activities, whereas the students do not have the option of tracking their peers and teachers' activities. This causes insecurity among the students, whether the teachers are there or not. The properties of IL do not allow teachers to have a relatively synchronous presence in the system when they are not posting things. Therefore, these messages may be a way of sustaining an embodied presence.

An additional relevant issue is the pedagogical idea in the course, which is that students should be active and teachers should be more in the background supporting the students and reading their posts. One common way to act in a more withdrawn role as a teacher in an asynchronous text-based environment is to be a tracker which is a strategy in which teachers read postings but do not add any or only add a few postings. This is what the teachers in the course in the IL setting did occasionally, and as a result there is a friction between the pedagogical idea and the material arrangement. In the technology used in this course, if you do not post, then you do not exist in the online environment. In other words, parts of the material arrangement, i.e., the LMS, do not fully support the pedagogical idea, or expressed with the concepts of Schatzki (2002), the teachers' intentionality collides with the limitations in the artefact. Being a lurker may not be the intention from the teachers' point of view, but the characteristics of the platform (i.e., not showing the teachers doings when 'just' reading postings) make the teacher look like they are in lurker mode. This causes one particular entity in the arrangement, the teacher, to step in and perform certain doings and sayings, mediating between the pedagogical idea and the LMS to get them to work together. In short, the teachers' sayings are supported by the platform but not their doings (i.e., that they have read a post). The doings must turn into sayings, like Teacher 2 states in the previous excerpt: 'I will follow your discussions regularly'. The teachers have to, by sayings, make a presence. In IL, teachers do not have a synchronous body that they can use to signal that they are present. They cannot just be there, like a bodily presence in an offline room. Yet, the level of presence can vary in an offline setting, given that being present bodily does not guarantee that the 
mind has not travelled elsewhere. Therefore, there is no guarantee that a presence is evident even when a body is onsite. The strategy of keeping oneself present is exemplified in the following excerpt from the SL setting:

Teacher 3: Well, you know, when I use podcasts... the real function... is to make sure to regard those students who could be anywhere... It's okay... you are still with us... You are, you see... I'm here... you're here... so to speak... That is, there is a social function, but of course, it is a function on the surface (interview-03).

This excerpt is consistent with Teacher 1's statement about writing 'meaningless messages'. Teacher 3 sometimes uses podcasts as supportive technology in the course, reassuring the students that Teacher 3 is there. Teacher 3 uses a number of asynchronous technologies to create a presence between the synchronous meetings. Podcasts is one of them and a Facebook group is another one. In the Facebook group, the teacher is embodied using a photograph and with text messages. To summarise, the teachers are embodying themselves online in various ways; typing themselves into being or creating podcasts, in order to be present. These teachers write or talk on a regular basis to ensure students that they are present throughout the course. In Schatzki's (1996) terminology, this can be perceived as a way of using their presence as an instrumental body. The instrumental body is used for achieving ends, and the teachers' ends are to attain an on-going teaching process that extends over a period of time. The instrumental body online can look quite different. In the IL setting, it is primarily about typing oneself into being and writing in order to teach. In the SL setting, it is primarily about talking in order to teach, but there are some instances of typing as well. In both settings, the teachers by their activities prefigure a safe environment and teacher presence throughout the course.

To achieve the ends of teaching, the teachers in this study use their embodiment in order to bring about a certain teaching situation. Next, three examples of how the teachers' bodies can be viewed as instrumental will be discussed. In the SL setting, most of the time spent online is in a classroom-like setting with chairs in rows that face an open space with screens on a wall. In this setting, Teacher 3 most often positions the body in this open space with the face turned toward the students sitting on the chairs. By positioning the body there, the teacher claims a space that is traditionally claimed by teachers, which is in front of a class. This signals that a certain type of teaching is likely to occur. Another example of using the body as instrumental is when Teacher 3 walks in front, alongside and behind the students when moving from one setting to another during class. As the teacher is walking ahead of the students, the teacher uses the body to guide and help the students navigate in the online space. It is not easy to move around and orient in a virtual world as a beginner. This way of acting can be perceived as using the instrumental body to reduce complexity in the educational setting for the students.

In the IL setting, the majority of the postings from the teachers could be found in spaces regarding the course outline, the course structure and the latest news on a bulletin board. The spaces designated for working groups were inhabited primarily by students, although the teachers occasionally intervened. Here, the teachers are focusing on reading, not posting. The coffee shop, which was a space for informal conversation, was also inhabited by students, 
and teachers were mainly absent there. By showing presence in some spaces and being more withdrawn in others signals how the teaching will be conducted. Through Schatzki's (1996) lens, the instrumental body is used to signal how the material arrangement is going to be used for teaching and learning.

\section{Discussion}

Apparently, teachers are embodied in several ways when teaching online. As seen in the SL setting, Teacher 3 was embodied by an avatar - a body image accompanied by a name and a voice which constitutes a synchronous bodily presence. The avatar could be understood as a cyborg body which comprises the dimensions of being a body, having a body (when breakdowns occur) and the instrumental body (which are used in order to achieve something pedagogically). Furthermore, Teacher 3 was embodied by an SL profile, although mostly with a default content such as a dummy, and also by insets in videos uploaded on the course web site and a profile in the Facebook group. Hence, multiple bodies (both offline and online ones) are in play when teaching takes place online. These bodies bundle with materialities in different ways, such as being positioned in a certain area in a certain way e.g. standing in an open space in front of students and using screens in order to show slides. This bundling presents both opportunities, such as using the avatar body in order to help students navigate, but also challenges, such as to juggle both teaching subject matter and manoeuvre the avatar.

In the IL setting teacher embodiment was done by posting a photo and 'writing' a body describing age, interests etc. (Teacher 1), or by leaving a default body in terms of a dummy (Teacher 2). However, this could also be understood as a matter of multiple bodies, since there was a body typing the messages, the profile body (in more or less detail) and the tracer of the body in terms of the text messages on the platform.

The analysis of the two empirical settings shows that it is possible to view the body as multiple, since both the offline body and online ones come into play and relate to each other in different ways. Mol has contended that the body could be seen as more than one, a multiple and manifold object, however not 'fragmented into being many' (2002, viii). This is in line with the findings in this article, since the online bodies hang together and also depends upon the offline body. The embodiments are multiple but not fragmented. There is no online embodiment that is not an extension of an offline one, since the online one needs to be typed by or manouvered by an offline one. When the offline body comes into play it raises questions about the dualism of online and offline. Perhaps the dualism is challenged when viewing the body as multiple. Hence, to teach online does not imply a disembodied existence but instead straddling an online-offline situation in which it is crucial to master a juggling of a body multiple. What the consequences of different ways to handle the bodies have for the students is an open question, but this study points towards a need to create awareness that bodies exist and that they need to be handled when teaching. Furthermore, the study shows that juggling bodies and using them for pedagogical purposes is a matter of professional skill in mastering a certain kind of ICT for pedagogical purposes. The notion that the teacher becomes a cyborg could, to a certain extent, be a fruitful figure of thought, although this does 
not mean agreeing with Haraway (1991) that a complete dissolution exists between humans and technology. Another way of understand it is in terms of what Land denote as 'a relational understanding of embodiment' $(2005,160)$ :

\footnotetext{
We are constituted by pre-existing forms of embodiment but our creation and subsequent use of new artefacts through our existing embodiment in turn transform that embodiment and reconstitute our identity, which always remains embodied .... Different technological contextualisations lead to our being differently embodied. $(2005,160-161)$
}

When analysing the empirical data based on Schatzki's (1996) concepts of being, having and instrumental body, it is clear that being a body can mean several things, the instrumental body can be used in different ways in order to bring about certain teaching situations and that having a body is a salient aspect when teaching in SL. Together, the particular online environment and the teacher's actions produce different sites where teaching takes place. Viewing teacher embodiment as existent and multiple adds a dimension to the concept of teacher presence online (cf. Mennecke et al. 2011). Teachers do not only show cognitive or social presence but also a bodily presence. The embodied presence online depends upon teacher judgements but also on what the online platform offers, e.g. what kind of bodies and bodily traces that are possible.

This article contributes in opening up questions about what it means for students and their learning that teachers' embodiment online differs from default to customised and that they are positioned and used in different areas on the platform. It also opens up questions of if it is better for the social situation that teachers have a customised body or not. Hence, further research on the significance for students and their learning of teachers' embodiment and its use is needed. Does, for instance, a customised body contribute to an increased sense of presence in comparison to a default body and an empty profile? And is students' learning processes affected by how teachers' positions themselves online? Limitations of the present study are the limited number of teachers and settings studied. Another limitation is that no follow up interviews were carried out with the teachers in order to elucidate why they chose to present themselves in the way they did.

In conclusion, this study shows that embodiment occurs online and furthermore that being a body involves being several bodies at the same time - a body multiple. It is therefore possible to reason about a presence that is corporeal, which in turn suggests a re-thinking and retheorising of presence in that it does not only concern cognitive and social presence, but also a bodily presence. Furthermore, teachers in this study exhibited understandings of the restrictions and possibilities of the technology when it came to what was made available in terms of tools for embodiment. Examples of how to handle restrictions are to express invisible doings when the technology does not show what the teacher do, and keeping oneself present during a course by 'meaningless messages' and podcasts. Examples of handling possibilities are to type oneself into being accompanying the text with a photo, or showing oneself in an inset in a video tutorial. However, the result also shows that stepping into embodied presence does not come by itself. This highlights the potential need for teacher training which could contribute to knowledge of that teachers do have bodies online and furthermore knowledge of available ways of embodiment in the particular ICT applied. 
Teachers in this study exhibit abilities in handling a body multiple and this could also be subject to teacher training. Finally, this study has showed that teachers use their bodies instrumentally and deliberately in order to bring certain teaching practices about. For instance, teachers' positioning of bodies in the arrangement signals what kind of teaching that will take place. Positioning of the online body in a virtual world also helps to reduce complexity for students.

\section{Acknowledgements}

I would like to thank Dr. Nick Hopwood from the University of Technology Sydney for valuable comments on an earlier version of this article.

\section{References}

Bayne, S. 2005. "Deceit, desire and control: The identities of learners and teachers in cyberspace." In Education in cyberspace, edited by R. Land and S. Bayne, 26-41. Abingdon: Routledge.

Boellstorff, T. 2008. Coming of age in Second Life: An anthropologist explores the virtually human. Princeton: Princeton University Press.

Boyd, D. 2008. "Why youth social network sites: The role of networked publics in teenage social life." In Youth, identity, and digital media, edited by D. Buckingham, 119142. Cambridge: MIT Press.

Castronova, E. 2005. Synthetic worlds: The business and culture of online games. Chicago: University of Chicago Press.

Fenwick, T., R. Edwards, and P. Sawchuk. 2011. Emerging approaches to educational research: Tracing the sociomaterial. Abingdon: Routledge.

Garrison, D. R., T. Anderson, and W. Archer. 2000. "Critical inquiry in a text-based environment: Computer conferencing in higher education." The Internet and Higher Education 2 (2-3): 87-105. doi:10.1016/S1096-7516(00)00016-6

Haraway, D. 1991. "A cyborg manifesto: Science, technology, and socialist-feminism in the late twentieth century." Chap. 8 in Simians, cyborgs, and women: The reinvention of nature. New York: Routledge.

Hine, C. 2008. "Virtual ethnography: Modes, varieties, affordances." In The SAGE handbook of online research methods, edited by N. Fielding, R.M. Lee, and G. Blank, 257-270. Los Angeles: Sage.

Hrastinski, S. 2009. Nätbaserad utbildning: En introduktion [Web based education: An introduction]. Lund: Studentlitteratur. 
Land, R. 2005. "Embodiment and risk in cyberspace education." In Education in cyberspace, edited by R. Land and S. Bayne, 149-164. Abingdon: Routledge.

Landri, P. 2012. "A return to practice: Practice-based studies of education." In Practice, learning and change: Practice-theory perspectives on professional learning, edited by $\mathrm{P}$. Hager, A. Lee and A. Reich, 85-100. Dordrecht: Springer.

Landri, P. 2009. "The fabrication of networked socialities." In Electronic constitution: Social, cultural, and political implications, edited by F. Amoretti, 207-223. Hershey: Information Age Publishers.

Lehman, R. M., and S. C. O. Conceição. 2010. Creating a sense of presence in online teaching: How to "be there" for distance learners. San Francisco: Jossey-Bass.

Mawer, M. 2011. "Categorising virtual worlds." In Reviewing perspectives on virtual worlds, edited by M. Savin-Baden, K. Wimpenny, M. Mawer, N. Steils, C. Tombs, and G. Tombs, 913. Coventry: Coventry University Press.

Mennecke, B. E., J. L.Triplett, L. M. Hassall , Z. J. Conde, and R. Heer. 2011. “An examination of a theory of embodied social presence in virtual worlds." Decision Sciences 42 (2): 413-450. doi:10.1111/j.1540-5915.2011.00317.x

Mol, A. 2002. The body multiple: Ontology in medical practice ( $2^{\text {nd }}$ printing 2005). Durham: Duke University Press.

Neustaedter, C., and E. Fedorovskaya. 2009. "Presenting identity in the virtual world through avatar appearance." In Graphics interface conference, edited by A. Ashurst Gooch and M. Tory, 25-27 May, held at Kelowna, Canada.

Orlikowski, W. J. 2007. "Sociomaterial practices: Exploring technology at work." Organization Studies 28 (9): 1435-1448. doi:10.1177/0170840607081138

Peachey, A., J. Gillen, D. Livingstone, and S. Smith-Robbins. 2010. "Editors' introduction: The physical and the virtual." In Researching learning in virtual worlds, edited by A. Peachey, J. Gillen, D. Livingstone, and S. Smith-Robbins, xv-xxviii. London: Springer.

Piccoli, G., R. Ahmad, and B. Ives. 2001. "Web-based virtual learning environments: A research framework and a preliminary assessment of effectiveness in basic IT skills training." MIS Quarterly 25 (4), 401-426. doi:10.2307/3250989

Reckwitz, A. 2002. "Toward a theory of social practices: A development in culturalist theorizing." European Journal of Social Theory 5 (2): 243-263.

doi:10.1177/13684310222225432

Schatzki, T. 2012. "A primer on practices.” In Practice-Based Education: Perspectives and Strategies, edited by J. Higgs, R. Barnett, S. Billett, M. Hutchings, and F. Trede, 13-26. Rotterdam: Sense Publishers. 
Schatzki, T. 2002. The site of the social: A philosophical account of the constitution of social life and change. University Park: Pennsylvania State University Press.

Schatzki, T. 2001. "Introduction: Practice theory." In The practice turn in contemporary theory, edited by T. R. Schatzki, K. Knorr Cetina, and E. von Savigny, 1-14. Abingdon: Routledge.

Schatzki, T. 1996. Social practices: A Wittgensteinian approach to human activity and the social. Cambridge: Cambridge University Press.

Srivastava, P., and N. Hopwood. 2009. "A practical iterative framework for qualitative data analysis." International Journal of Qualitative Methods 8 (1), 76-84. url:

http://ejournals.library.ualberta.ca/index.php/IJQM/article/view/1169/5199

Steils, N. 2011. "Avatar creation, appearance and behavior: Exploring self-presentation in virtual worlds." In Reviewing perspectives on virtual worlds edited by M. Savin-Baden, K. Wimpenny, M. Mawer, N. Steils, C. Tombs, and G. Tombs, 26-32. Coventry: Coventry University Press.

Sundén, J. 2002. “Material virtualities: Approaching online textual embodiment.” PhD diss., Linköping University.

Taylor, T. L. 2002. "Living digitally: Embodiment in virtual worlds." In The social life of avatars: Presence and interaction in shared virtual environments, edited by R. Schroeder, 40-62. London: Springer.

Williams, M. 2007. "Avatar watching: Participant observation in graphical online environments." Qualitative Research 7 (1), 5-24. doi:10.1177/1468794107071408 